\title{
Investigations on in vitro survival and virulence of T. pallidum under aerobiosis
}

\author{
T. RATHLEV \\ Treponematoses Laboratory, State Serum Institute, Copenhagen, Denmark
}

Cultivation in vitro of the pathogen Treponema pallidum has been studied for nearly 50 years without success. Intensive efforts were made, especially before the introduction of penicillin therapy, to propagate the organisms in various media and in tissue or egg cultures. Some of these investigations had success in maintaining the motility of the organisms for several days but showed consistent failure in maintaining the virulence for more than 2 to 3 days.

Noguchi (1912) studied in vitro cultivation of the pathogenic treponemes in various tissues, such as kidney, muscle, or testes from horse, sheep, and rabbit under anaerobic conditions. Virulence was not maintained beyond a short period. Bessemans and de Geest (1928) grew $T$. pallidum in media with rabbit serum and in ascitic fluid albeit virulence was lost quickly. Extensive work was carried out by Gammel and Ecker (1931) to maintain the survival of the organisms under variable conditions. Although the motility of the organisms was observed for several days, virulence disappeared in 48 hours. Similar observations were reported by Kast and Kolmer (1933).

One aspect common to all these studies was the use of anaerobiosis for the in vitro cultivation of the treponemes since, according to the classical taxonomy of micro-organisms, pathogenic $T$. pallidum was regarded as a strict anaerobe. However, the anaerobiosis of this organism has never been explained satisfactorily in view of its survival and virulence in human or animal lesions exposed to atmospheric oxygen. As reported by Stanier, Doudoroff, and Adelberg (1970), obligate anaerobes on the other hand are strongly inhibited or killed by exposure to oxygen.

Recent work by McCord, Keele, and Fridovich (1971) provides some basis to explain the enigmatic anaerobiosis of $T$. pallidum. They showed that, among 26 different micro-organisms studied, all aerobes possessed two enzymes, catalase and superoxide dismutase. Anaerobes possessed neither of the two enzymes, with the exception of two species that contained very low concentration of catalase. On the other hand, all aerotolerant anaerobes, which do not develop a cytochrome chain, possessed intermediate levels of the enzyme, superoxide dismutase, but no catalase. This was true for all aerotolerant anaerobes with the exception of Lactobacillus plantarum.

The study presented here utilizes various interesting observations made during another study by Rathlev (1975b) on the direct cytotoxicity of $T$. pallidum-sensitized rabbit lymphocytes to virulent treponemes. In the latter investigation, in vitro longevity of $T$. pallidum was supported by the use of a new medium, which was used in the present study.

The investigation reported here was based on the observation that $T$. pallidum tolerates reduced amounts of molecular oxygen if the toxic metabolites are neutralized or removed, and may need low concentrations of oxygen to maintain virulence. For this assumption it is necessary for the medium to contain materials to provide the required nutrients, $\mathrm{pH}$, redox potential as well as enzymes to detoxify the harmful superoxide, $\mathrm{O}_{2}^{-}$radicals, and hydrogen peroxide produced that may inhibit virulence and multiplication of the organisms.

Since replication and maintenance of virulence of $T$. pallidum, rather than just a continuation of its motility, are the key factors for successful cultivation in vitro, this investigation attempts to study the conditions that may influence these factors when $T$. pallidum is cultivated in vitro under aerobic conditions.

\section{Material and methods}

\section{MEDIUM USED FOR CULTIVATION}

Powder McCoy's 5a medium was supplemented and prepared for use as follows. To the dry contents of a package (for 1 litre liquid medium) were added $400 \mathrm{mg}$. glutathione, $100 \mathrm{mg}$. sodium pyruvate, and enough HEPES (N-2 hydroxyethyl piperazine- $\mathrm{N}^{\prime}-2$ ethanesulphonic acid) organic buffer to produce a final concentration of $28 \mathrm{mM}$ HEPES. The contents were dissolved in distilled $\mathrm{H}_{2} \mathrm{O}$ and the volume was adjusted to 1 litre and had a $\mathrm{pH}$ of $7 \cdot 2$. Adequate volume of the medium was mixed with inactivated fetal calf serum in the ratio of $17: 3(\mathrm{v} / \mathrm{v})$. 
The final mixture was sterilized by passage through a Nalgene filter unit, $0.2 \mu$ plain membrane. On the basis of the results reported by Rathlev (1975b), this mediumhereafter designated suppl. McCoy's 5a-was found to be superior to unsupplemented McCoy's 5a medium or a mixture of 0.85 per cent. saline and inactivated normal rabbit serum $1: 1(\mathrm{v} / \mathrm{v})$ for the in vitro longevity of the virulent treponemes.

\section{PATHOGENIC TREPONEMES}

$T$. pallidum (Nichols strain) was propagated in adult male albino rabbits by intratesticular injections. When orchitis developed, the rabbits were exsanguinated and the testes were removed under sterile conditions. Excess fat or blood vessels having been removed, the testes were cut across their length, washed with physiological saline, and then placed in a $200 \mathrm{ml}$. Erlenmeyer flask fitted with a screw cap. Six to eight testicles were shaken gently with $100 \mathrm{ml}$. of the medium described above in a $34-35^{\circ} \mathrm{C}$ water bath for $30 \mathrm{~min}$.

Treponemal suspension was partially purified by centrifugation at $34^{\circ} \mathrm{C}$ for $5 \mathrm{~min}$. at $400 \mathrm{G}$. Heavier host tissue, such as spermatozoa, leucocytes, and erythrocytes, was thus sedimented. The supernatant was gently removed and kept at $34^{\circ} \mathrm{C}$ until ready for use.

In experiments in which cultured mammalian cells were used, the partially purified treponemal suspension was separated from light, particulate host-tissue by the procedure described by Rathlev (1975a) in which $T$. pallidum suspension was centrifuged over a column of Ficoll and Triosil to yield virulent concentrated treponemes.

\section{TREPONEMAL COUNT}

The treponemes purified by both the procedures were examined and counted accurately by darkfield microscopical examination of $5 \mu$. of the suspension. The number of the organisms per $\mathrm{ml}$. was calculated by counting treponemes in 25 fields and by measuring the area of the cover slip and the diameter of the field. The treponemal suspension was adjusted to contain $10^{7}$ organisms $/ \mathrm{ml}$. by addition of either more medium or purified treponemes.

\section{ANTIBIOTICS}

Contamination of the in vitro cultures of $T$. pallidum by other micro-organisms can be a serious problem when long-term survival is planned. Some strains of the pathogenic and the non-pathogenic treponemes were reported by Abramson and Smibert (1971) to be insensitive to various antibiotics at different concentrations. Four of these antibiotics (viomycin, kanamycin, gentamycin (garamycin), and neomycin) were added separately to $T$. pallidum suspensions at three concentrations, viz. 50, 100, and $500 \mu \mathrm{g} / \mathrm{ml}$. of the medium. No antibiotic was present in the control tube.

\section{ENZYMES}

Catalase, and superoxide dismutase prepared from bovine erythrocytes, were added to the medium used for the cultivation of the treponemes in cultured fibroblastic cells from rabbit testes. The concentrations of the enzymes were $100 \mu \mathrm{g} . / \mathrm{ml}$. for catalase and $50 \mu \mathrm{g} . / \mathrm{ml}$. for superoxide dismutase.

\section{CELLS}

Fibroblastic cells from monolayer cultures prepared from normal rabbit testes tissue were used for in vitro cultivation of $T$. pallidum. The medium used to attain growth and confluency of the cells was the unsupplemented McCoy's 5 a medium fortified with 10 per cent. ( $v / v$ ) inactivated fetal calf serum. Before the addition of $10^{6}$ treponemes to the cells from Leighton culture tubes, the original medium was changed to the suppl. McCoy's 5 a medium containing $100 \mu \mathrm{g} . / \mathrm{ml}$. gentamycin, $100 \mu \mathrm{g} . / \mathrm{ml}$. catalase, and $50 \mu \mathrm{g} .1$ $\mathrm{ml}$. superoxide dismutase.

The medium and the cells from three different culture tubes were removed at the intervals of $24,48,96$, and $144 \mathrm{hrs}$ after the addition of $T$. pallidum. At each interval, treponemes from the pooled medium were sedimented by centrifugation at $34^{\circ} \mathrm{C}$ to remove the antibiotic and the enzymes. One ml. treponemal suspension containing $10^{7}$ motile organisms in 0.85 per cent. saline and rabbit serum $(1: 1)$ was tested for virulence by injecting the right testicle of a normal rabbit. As a control, the left testicle was infected with the same number of fresh virulent treponemes.

The cells attached to the surface of the culture tubes were gently removed, suspended in the medium, counted in a haemocytometer, and sonicated to disrupt only the cells. A count and observation of the motility of the treponemes (approx. 10 per cent. of the original count) that were either inside the cells or had adhered to them, were carried out by darkfield microscopy and the organisms were injected intratesticularly in another rabbit as described above.

Fresh, washed, rabbit erythrocytes were packed to approx. $1 \mathrm{ml}$. by gentle centrifugation in three $8 \mathrm{ml}$. glass tubes. T. pallidum suspension in suppl. McCoy's 5a medium containing $10^{7}$ treponemes $/ \mathrm{ml}$. was layered over the packed erythrocytes and kept at $34^{\circ} \mathrm{C}$ in different tubes. Motility observations were made at $48-\mathrm{hr}$ intervals.

\section{Results and discussion}

McCoy's $5 \mathrm{a}$ medium is rich in several nutrients needed for the survival of $T$. pallidum and the mammalian cells used in the cultivation experiments. Supplementation of the medium with glutathione and sodium pyruvate provided two important factors for the longer survival of the organisms.

In the earlier studies, different media were usually buffered by the addition of sodium bicarbonate, which has a very limited buffering capacity, and the $\mathrm{pH}$ of the media changed rapidly. Acid production in the medium induced contamination by other organisms and highly alkaline $\mathrm{pH}$ values proved to be toxic to the treponemes. Organic HEPES buffer stabilizes the $\mathrm{pH}$ of the medium for a long period. Maintenance of the optimum $\mathrm{pH}$, approx. $7 \cdot 2$, seemed to be a very important factor for the long-term survival of $T$. pallidum. 
The effect of different concentrations of the four antibiotics on the in vitro survival of $T$. pallidum is presented in the Table. The results are an average of four experiments.

The results indicate that viomycin, kanamycin, and neomycin, though not nearly as toxic to $T$. pallidum as penicillin, were inhibitory at the concentrations used. Gentamycin, on the contrary, showed complete non-toxicity to the organisms and a possible stimulatory effect on the survival of $T$. pallidum.

Two tubes containing the virulent treponemes in suppl. McCoy's 5a medium containing $100 \mu \mathrm{g} . / \mathrm{ml}$. gentamycin but no cells, were misplaced after approx. 4 weeks though they were still kept at $34^{\circ} \mathrm{C}$. When the tubes were found and the contents examined by microscopy, long strands of a fungus resistant to gentamycin were found to have grown and settled at the bottom of the tube. Usually, such a mishap would not be worth reporting except for the unusual accompanying circumstances. The medium was clear and the $\mathrm{pH}$ was still $7 \cdot 2$ and the treponemes were very motile. These conditions persisted for approx. 60 days longer with more growth and branching of the 'Mucor species' fungus accompanied by a decrease in treponemal motility. One possible explanation is that the rapidly growing fungus provides a continuous rich source of the detoxifying superoxide dismutase and other factors which $T$. pallidum is unable to produce adequately for a longer period.

The protective and possibly stimulatory effect of gentamycin on the in vitro existence of $T$. pallidum was observed so consistently that it was added to the medium at the concentration of $100 \mu \mathrm{g} . / \mathrm{ml}$. in all the experiments. However, treponemes were always separated by centrifugation from the antibiotic and the enzymes before injection into the rabbits.

The superiority of gentamycin over the three other antibiotics was evaluated by its non-toxicity, broadspectrum activity, and a possible stimulatory effect on the survival of virulent treponemes at subinhibitory levels. This antibiotic belongs to the aminoglycoside group and is extremely stable in the $\mathrm{pH}$ range of 2 to 10 at $37^{\circ} \mathrm{C}$ and to autoclaving. It has been shown by Schafer and Pascale (1971) to be non-toxic for DNA and RNA viruses at a high concentration of $2 \mathrm{mg} . / \mathrm{ml}$.

The results of this study, as compared to those from the earlier investigations under anaerobiosis, show that the motility of $T$. pallidum and its virulence under aerobic conditions were maintained for a longer period in the presence of viable cells which supply superoxide dismutase.

Besides the use of a new medium, stabilization of the $\mathrm{pH}$ and a reduced, though not monitored, oxygen pressure seemed to enhance the survival of the organisms.

In order to infect the cultured cells for the in vitro cultivation, removal of the light particulate host tissue from the $T$. pallidum suspension was essential. Centrifugation on a Ficoll-Triosil column removed a variety of host cells that interfere with the uniformity of the cultured cells. Removal of granulocytes or phagocytic cells was important, since their presence induces acidity in the medium and, as shown by Babior, Kipnes, and Curnutte (1973), their phagocytic activity results in the production of the toxic superoxide radicals.

The effect of the addition of the enzymes, catalase and superoxide dismutase, on the virulence and survival of $T$. pallidum cannot be clearly evaluated, since the enhancement observed was only in the degree of motility during the first 12 to $18 \mathrm{hrs}$. The maintenance of virulence did not change significantly when the enzymes were added to $T$. pallidum suspension in a cell-free medium. These results could be due to the use of inadequate amounts of the enzymes. But the results on the virulence and motility of $T$. pallidum in the presence of cultured cells, erythrocytes, and even the fungus, indicate that a continuous source of the enzymes from viable respiring cells was more effective.

The virulence of the treponemes from the tissue culture medium or the sonicated cells was evaluated by the degree of orchitis or, more precisely, by the number of organisms extracted from the infected testicle as compared to the control. From previous experience, infection in each rabbit testicle, excepting the drainage by the regional lymph node, seems to be localized until orchitis develops. The two testicles can therefore be injected differently for comparing different treatments. The intratesticular route of infection was preferred in this study since the treponemes extracted could be counted more accurately than those present in an intradermal lesion.

The total counts of viable treponemes extracted per

TABLE Maintenance of motility of 50 per cent. or more treponemes in suppl. McCoy's 5 a medium in the presence of antibiotic

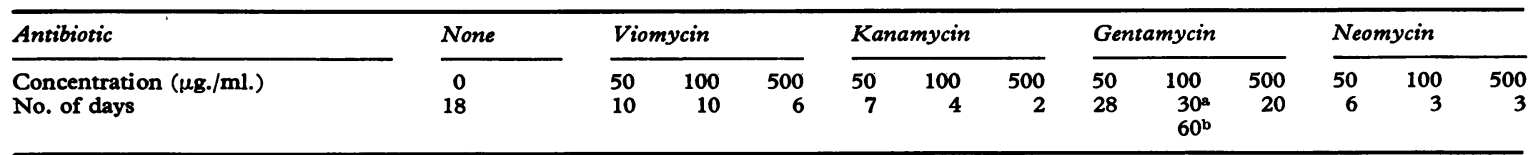

- Days motility observed without any contamination

- Days motility observed after production of 'long stranded' fungus in some tubes 
testis after the development of orchitis produced by injecting $10^{7}$ organisms are presented in the Figure.

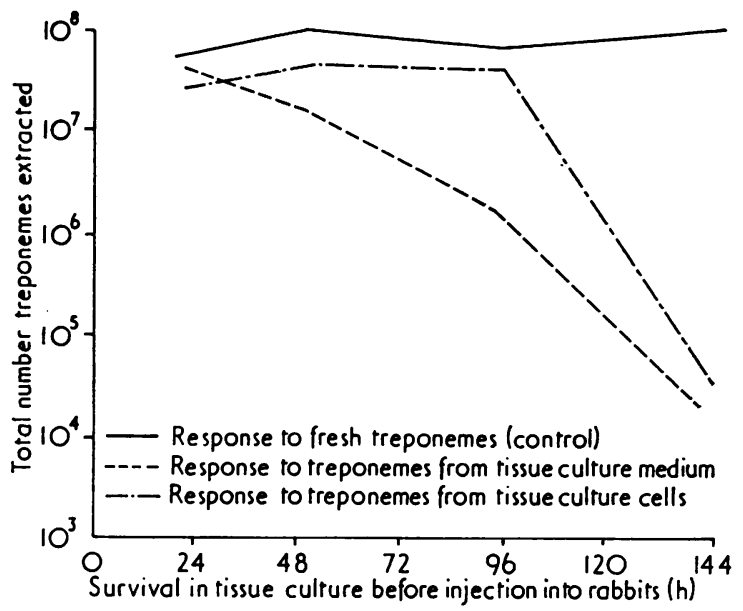

FIGURE Treponemal count. Total number extracted per testis after orchitis produced by injection of $10^{7}$ treponemes

The results show an approximately 10 -fold increase in the number of treponemes after intratesticular injection of $10^{7}$ freshly isolated treponemes. However, the numbers of organisms extracted after intratesticular infection with $T$. pallidum maintained in tissue culture were considerably less. The virulence of the treponemes from the tissue culture medium decreased between 24 and $144 \mathrm{hrs}$ as evaluated by intratesticular multiplication. On the other hand, the number of treponemes extracted after intratesticular injection of the organisms from sonicated cultured cells increased slightly during the first $96 \mathrm{hrs}$ of in vitro cultivation. After $144 \mathrm{hrs}$ of survival in tissue culture, the virulence of $T$. pallidum, as indicated by the counts, decreased considerably and their motility was very sluggish.

Since the intracellular location of treponemes was not established in this study, it is premature to draw conclusions from the slight difference in maintenance of virulence of the organisms present in the medium and the sonicated cells.

Careful counts of the treponemes made at different stages of the experiments showed no multiplication or increase in their number. $T$. pallida isolated after ultrasonic disruption of the cultured cells were included in the total count regardless of their possible intracellular residence or simple adherence to the cells. No attempts were made in this study to investigate this problem. A detailed study of the virulence of the intracellular treponemes, if they do exist, is planned with the help of scanning electron microscopy.
The division time for $T$. pallidum is 30 to $33 \mathrm{hrs}$ and yet replication of the organism in in vitro cultures was not observed. Perhaps this indicates that some important mechanism that operates in vivo is still not duplicated under the new in vitro conditions of cultivation. To what extent the series of events, beginning with the loss of replication, then of virulence, and finally of the motility of the organisms, represents a phenotypic or a genotypic adaptation is at present only a matter of nebulous speculation.

Tissue culture of $T$. pallidum comprises a symbiotic existence of aerotolerant anaerobes and aerobic mammalian cells. By necessity conditions have to be made more favourable for the growth of $T$. pallidum. If the multiplication and maintenance of virulence of the treponemes are affected by their presumably low content of superoxide dismutase, a continuous supply of the enzymes catalase and particularly of superoxide dismutase is indicated. According to McCord and others (1971), dismutation of the toxic superoxide, $\mathrm{O}_{2}^{-}$radicals, is perhaps the most important activity that enables micro-organisms to survive in the presence of molecular oxygen. The enzymic protection can perhaps be supported by the addition of an antioxidant, such as $\alpha$-tocopherol, which can minimize the toxic effects of the superoxide and peroxide radicals produced.

In this preliminary study, excess oxygen was avoided simply by filling the tubes with the medium to at least 90 per cent. of their capacity and by the use of materials to reduce and to dismutate the toxic metabolites. In future investigations, monitored reduced oxygen pressure in the culture tubes or vessels should be used. Reduced oxygen levels are not harmful to the viability of the cultured mammalian cells used for $T$. pallidum cultivation. In fact, respiring cells tolerate reduced oxygen better than high pressure oxygen which is toxic to all living cells.

\section{Summary}

Motility of pathogenic $T$. pallidum was maintained in aerobic in vitro cultures for several weeks using a special medium. The latter consisted of McCoy's 5a medium supplemented with glutathione, sodium pyruvate, HEPES buffer, gentamycin (garamycin), and fetal calf serum. The virulence of the organisms was lost in 5 to 6 days. No multiplication of the organisms was observed.

Four antibiotics (viomycin, kanamycin, gentamycin (garamycin), and neomycin) were tested for their bactericidal action and possible toxicity to $T$. pallidum. Gentamycin proved to be superior to the other three antibiotics in being non-toxic to the treponemes and showing a possible stimulatory effect on their motility and longevity.

Cultivation of $T$. pallidum in cultured cells in the presence of the enzymes, superoxide dismutase and 
catalase, in a special medium showed possibilities for future experimentation under monitored, reduced oxygen pressure with a continuous system to dismutate superoxide radicals.

This investigation was supported by a grant from the World Health Organization. The author thanks Anne Knudsen and Connie Kjer for technical assistance, Dr. J. Bang for supplying various antibiotics, and Dr. J. Leerhøj for suggestions on tissue culture procedure used at the Serum Institute.

\section{References}

Abramson, I. J., and SmIBerT, R. M. (1971) WHO/VDT/ RES, 71.246

BABIOR, B. M., Kipnes, R. S., and CuRnutte, J. T. (1973) f. clin. Invest., 52, 741
Bessemans, A., and de Geest, B. (1928) C. R. Soc. Biol. (Paris), 99, 1877

Gammer, J. A., and Ecker, E. E. (1931) Arch. Derm. Syph., 23, 439

Kast, C. C., and Kolmer, J. A. (1933) Amer. F. Syph., 17, 533

McCord, J. M., Keele, B. B., and Fridovich, I. (1971) Proc. nat. Acad. Sci., 68, 1024

NoGuchi, H. (1912) F. exp. Med., 15, 90

RAtHLev, T. (1975a) Acta path. microbiol. scand., Sect. B, 83, 157

(1975b) To be published

Schafer, T. W., and Pascale, A. (1971) Bact. Proc., P 226

Stanier, R. Y., Doudoroff, M., and Adelberg, E. A. (1970) 'The Microbial World', 3rd ed., p. 75. Prentice Hall Inc., Englewood Cliffs, N.J. 